\title{
Report of the Korean Association of External Quality Assessment Service on Qualitative Testing of Molecular Virology (2016-2020)
}

\author{
Kuenyoul Park ${ }^{\circledR}$, Mi-Na Kim ${ }^{\circledR}$, and Heungsup Sung ${ }^{\oplus}$ \\ Department of Laboratory Medicine, Asan Medical Center, University of Ulsan College of Medicine, Seoul, Korea
}

\section{Corresponding author:}

Heungsup Sung

Department of Laboratory Medicine, Asan Medical Center, University of Ulsan College of Medicine, 88 Olympic-ro 43gil, Songpa-gu, Seoul 05505, Korea Tel +82-2-3010-4499

E-mail sung@amc.seoul.kr
This is an Open Access article distributed under the terms of the Creative Commons Attribution Non-Commercial License (http://creativecommons.org/licenses/ by-nc/4.0) which permits unrestricted non-commercial use, distribution, and reproduction in any medium, provided the original work is properly cited.
For this study, we reviewed the surveys on qualitative testing of molecular virology conducted by the Korean Association of External Quality Assessment Service from 2016 to 2020 . For this proficiency testing, biannual quality control samples are provided and two or three samples per item are delivered to participating institutions for a trial. During the study period, the number of participating institutions had decreased for cytomegalovirus (CMV); was unchanged for human immunodeficiency virus type 1 (HIV-1); and had increased for Epstein-Barr virus (EBV), human papillomavirus (HPV), and respiratory viruses comprising adenovirus, influenza virus, parainfluenza virus, and respiratory syncytial virus (RSV). Only one or two institutions had incorrect results for CMV, EBV, HPV, and HIV over the 5-year period, except for one CMV sample in the second trial in 2019, for which four institutions reported false-negative results. In 2016, respiratory virus proficiency testing showed $10(14 \%)$ and $30(41 \%)$ institutions with false responses to influenza and RSV. In 2017, 22 institutions (24\%) responded with false-negative results for adenovirus in the first trial, and 30 institutions (33\%) responded with false-positive results due to contamination during sample preparation in the second trial. Some unacceptable results were likely due to clerical errors and the low sensitivity of laboratory-developed tests. In conclusion, this report suggests that proficiency testing is helpful for improving laboratories' performances in qualitative molecular virology test reporting and highlights the importance of adequate quality control material production.

(Lab Med Qual Assur 2021;43:130-137)

Key Words Proficiency testing, Quality assurance, Molecular virology, Qualitative testing

감염을 진단하는 데 도움이 된다. 면역억제자에서 CMV 망막염 진 단을 위해 안방수나 유리체액에서 CMV 핵산을 정성적으로 검출 할 수 있다[1]. Epstein-Barr virus (EBV)의 경우 핵산 정량검사 가 $\mathrm{EBV}$ 혈증 진단과 추적관찰을 위해 추천된다. 이전에는 $\mathrm{EBV}$ 혈증 선별을 위해 EBV 핵산 정성검사를 주기적으로 시행하다 
가 양성인 경우 핵산 정량검사를 실시하기도 하였다[2]. Human papillomavirus (HPV)는 자궁경부 질환의 선별과 관리를 위 해 핵산증폭기술(nucleic acid amplification technologies, NAATs)이 진단의 가장 중요한 위치를 점하고 있다[3]. Human immunodeficiency virus type 1 (HIV-1)의 경우 항체검사가 표준진단법이지만[4], 최근에는 HIV 진단에 핵산증폭검사가 사 용되기 시작하였다. 공여자 선별검사 용도로 Procleix ULTRIO and Discriminatory HIV-1/HCV/HBV assays (Gen-Probe Inc., San Diego, CA, USA)나 COBAS AmpliScreen HIV-1 test (Roche Molecular Systems, Pleasanton, CA, USA)와 같은 정성 분자검사가 사용되었고, APTIMA HIV-1 RNA qualitative assay (Gen-Probe Inc., San Diego, CA, USA)의 경우 급성 HIV 증후군(acute HIV syndrome) 진단에 사용할 수 있다[5,6]. APTIMA HIV-1 RNA qualitative assay는 신생아 HIV-1 감염 진 단을 위해서도 사용될 수 있는데, 산모에게 전달받은 항체를 가진 신생아의 HIV-1 감염 진단에 유용하다[7]. 호흡기바이러스의 경우 에는 증상과 징후에 따라 원인 개별 바이러스를 구분할 수 없기 때 문에 한꺼번에 여러 종류의 바이러스를 검출할 수 있는 다종 분자 진단검사가 표준검사법이 되었다[8]. 저자들은 2016년부터 2020 년까지 대한임상검사정도관리협회 신빙도조사사업 바이러스 분 자검사 항목 중 정성 바이러스 분자검사에 대해 그 내용과 결과를 보고하고자 한다.

\section{재료 및 방법}

\section{1. 신빙도조사 방법 및 대상기관}

2016년부터 2020년까지 년 2회 총 10회에 걸쳐 CMV, EBV, HIV-1, HPV, adenovirus, influenza virus, parainfluenza virus (PIV), respiratory syncytial virus (RSV) 정성 분자검사 신 빙도조사를 실시하였다. 2016-2020년에 바이러스 분자검사에 신청한 기관은 각각 $96,119,121,121,125$ 개였으며, 냉동 검체 발송 일정에 맞추어 연 2회 발송하였다. 모든 신청과 결과입력, 결 과판정 등은 대한임상검사정도관리협회 홈페이지에 구축된 신빙 도조사 프로그램(http://eqas.keqas.org/)을 이용하였다.

\section{2. 관리물질 제조}

2016-2020년 CMV, EBV, HIV-1 신빙도조사사업을 위한 정 도관리물질은 National Institute for Biologic Standards and Control (NIBSC, Hertfordshire, UK)에서 구입한 World Health Organization International Standards 09/162 (CMV), 09-260 (EBV), 16/194 (HIV-1)을 폐기 예정인 신선동결 혈장에 희석하여 제조하였다. 폐기 예정된 신선동결 혈장 사용은 서울아
산병원 임상연구심의위원회의 심의면제 승인을 받았다. HPV 양 성 검체는 HPV-18 유전체를 가지고 있는 HeLa 세포 또는 HPV16 유전체를 가지고 있는 $\mathrm{SiHa}$ 세포를 희석하여 소변에 희석하여 제조하였으며, 음성 검체의 경우 불멸화 사람 $\mathrm{T}$ 림프구인 Jurkat 세포를 Eagle's Minimum Essential Medium에 희석하여 제조 하였다. Adenovirus, influenza virus, PIV 1-3, RSV는 R-Mix TOO 세포(Quidel, San Diego, CA, USA)에 배양 후 Universal Transport Medium (UTM; Copan, Brescia, Italy)에 희석하여 제조하였다. 호흡기바이러스 음성 검체는 MRC-5 세포를 UTM에 희석하여 제조하였다. 제작이 완료된 검체는 $-70^{\circ} \mathrm{C}$ 의 초저온 냉 동고에 보관 후 운송 일정에 맞춰 냉동상태로 대한임상검사정도관 리협회로 배송, 제조물질을 인계하였으며, 인계 시 인수인계증을 통해 물질의 수량 및 상태를 재확인하였다. 제조된 정도관리물질 의 평가시험에 사용된 검사, 시약장비는 Table 1 에 기술하였다.

\section{3. 결과 판정 및 해석}

정성 결과는 의도된 결과와 일치하는 경우 'acceptable'하다고 판정하였다. 이 기준에 맞지 않은 응답을 하거나 응답하지 않은 경 우 'unacceptable'로 판정하였다. 정성 결과가 80\% consensus (전체 기관의 결과값의 $80 \%$ 일치)에 미달하면 판정을 보류하거나 제외하였다.

\section{결과}

\section{1. 참여기관 수 및 검사방법}

2020년 2회차 대한임상검사정도관리협회 미생물 분자검사 신 빙도조사사업 항목 중 정성검사의 결과를 보고한 기관 수와 각 항목별로 사용한 검사키트의 제조사 및 키트를 조사한 결과는 Table 2와 같다. CMV의 경우 Biocore사(5/20)와 Biosewoon사 (5/20)의 제품을 가장 많이 사용하였으며, EBV의 경우 Biocore 사 $(5 / 20)$ 의 제품을 가장 많이 사용하였다. HIV-1의 경우 Roche 사 제품을, HPV의 경우에는 Seegene사(14/46)와 Roche사 (14/46)의 제품을 가장 많이 사용하였다. 호흡기바이러스의 경우 에는 Seegene사의 Allplex Respiratory Panel 1,2,3 (Seegene, Seoul, Korea)을 37기관에서, LG화학의 Advansure RV Realtime reverse transcription-polymerase chain reaction (RTPCR) (LG Chem, Seoul, Korea)과 Advansure RV-Plus Realtime RT-PCR (LG Chem, Seoul, Korea)을 각각 24기관과 16기 관에서 사용하여 대부분의 기관이 Seegene사와 LG화학의 제품 을 사용하고 있었다. 항목별 참여기관 수는 2016년과 2020년을 대비해 볼 때, CMV는 25기관에서 21기관으로 소폭 감소하였고, $\mathrm{EBV}$ 는 15 기관에서 16 기관으로, $\mathrm{HPV}$ 는 43 기관에서 47 기관으로, 
HIV-1은 3기관 그대로 차이가 없었다. 호흡기바이러스의 경우에 는 항목별로 약간의 차이가 있지만 2016년 70-73기관에서 2020 년 97-102기관으로 참여기관 수가 증가하였다.

\section{2. 항목별 결과분석}

\section{1) CMV}

2016년에서 2020년까지 5년간 신빙도조사사업의 각 검체당 회신한 CMV 검사결과를 모두 분석하였다(Table 3). 2016년 1차 세번째 검체에서 위음성을 보고한 기관이 1 기관, 2 차 두번째 검체 에서 위음성을 보고한 기관이 1기관 있었다. 2018년 2차에서는 1 기관이 첫번째 검체와 세번째 검체에서 각각 양성을 음성으로, 음 성을 양성으로 보고하였다. 2019년에는 1차에서 세번째 검체를 3 기관이 위음성 보고를, 2 차의 두번째와 세번째 검체에서 각각 1 기 관과 4 기관에서 위음성 보고를 하였다.

\section{2) EBV}

2016년에서 2020년까지 5년간 신빙도조사사업의 각 검체당 회신한 EBV 검사결과를 모두 분석하였다(Table 3). 2017년 1차 에 두번째 검체를 위음성 보고한 기관이 1기관, 2017년 2차에 세 번째 검체를 위음성 보고한 기관이 2기관 있었다. 2020년에는 2 차에 1 기관이 첫번째와 두번째 검체를 각각 위양성과 위음성 보고 하였고, 다른 1 기관이 세번째 검체에 대해 위음성 보고하였다.

\section{3) HPV}

2016년에서 2020년까지 5년간 신빙도조사사업의 각 검체당 회신한 HPV 검사결과를 모두 분석하였다(Table 3). 2016년 1차 에서만 1 기관이 위음성 보고를 하였고, 그 외에 2017년에서 2020 년까지는 모든 기관이 $100 \%$ 의 정답률을 보였다.

\section{4) HIV-1}

2016년에서 2020년까지 5년간 신빙도조사사업의 각 검체당 회신한 HIV-1 검사결과를 모두 분석하였다(Table 3). 2016년 1 차에서 1 기관이 두번째와 세번째 검체를 모두 위음성 보고하였고, 2017년 1차에서도 다른 1기관이 두번째와 세번째 검체를 모두 위 음성 보고하였다. 2018년에는 1차에 2기관이 두번째와 세번째 검 체에 대해 위음성 보고를 시행하였으며, 2차에서는 이 2기관 중 1 기관이 첫번째와 두번째 검체를 위양성 및 위음성 보고하였다. 2018년에 잘못 응답한 2기관은 모두 신속항체검사를 실시한 후 분자검사로 잘못 입력하였다. 2019년과 2020년에는 모든 기관이 $100 \%$ 정답률을 보였다.

\section{5) 호흡기바이러스}

2016년에서 2020년까지 5년간 신빙도조사사업의 각 검체당 회신한 호흡기바이러스 검사결과를 모두 분석하였다(Table 4). 2016년 1차에서는 influenza virus에 대해서 양성 검체를 73기 관 중 10 기관에서 위음성 보고하였고, RSV에 대해 72 기관 중 1 기 관이 위음성 보고하였다. 2016년 2차에는 adenovirus를 1기관 이 위음성 보고하였고, RSV 양성 검체를 73 기관 중 31 기관이 위

Table 1. Tests used for checking homogeneity, stability, and adequacy of control specimens for qualitative molecular proficiency tests

\begin{tabular}{llll}
\hline \multicolumn{1}{c}{ Test items } & \multicolumn{1}{c}{ Technology } & \multicolumn{1}{c}{ Instruments } & \multicolumn{1}{c}{ Reagents } \\
\hline CMV & Quantitative real-time PCR & m2000 RealTime System & RealTime CMV Assay (Abbott) \\
EBV & Quantitative real-time PCR & m2000 RealTime System & RealTime EBV Assay (Abbott) \\
HIV-1 & Quantitative real-time RT-PCR & cobas 6800 System & cobas 6800 HIV-1 Test \\
HPV & Multiplex real-time PCR & m2000 RealTime System & Abbott RealTime High Risk HPV \\
Adenovirus & Multiplex real-time RT-PCR & Hamilton Microlab STARlet and CFX-96 & Allplex Respiratory Panel \\
Influenza virus & Multiplex real-time RT-PCR & Hamilton Microlab STARlet and CFX-96 & Allplex Respiratory Panel \\
PIV 1-4 & Multiplex real-time RT-PCR & Hamilton Microlab STARlet and CFX-96 & Allplex Respiratory Panel \\
RSV & Multiplex real-time RT-PCR & Hamilton Microlab STARlet and CFX-96 & Allplex Respiratory Panel \\
\hline
\end{tabular}

The instruments and reagents used were as follows: m2000 RealTime system (Abbott, Des Plaines, IL, USA), Cobas 6800 (Roche Molecular Diagnostics, Pleasanton, CA, USA), Hamilton Microlab STARlet (Hamilton Robotics, Reno, NV, USA), CFX-96 (Bio-Rad, Hercules, CA, USA), RealTime CMV Assay (Abbott, Des Plaines, IL, USA), RealTime EBV Assay (Abbott Des Plaines, IL, USA), Cobas 6800 HIV-1 Test (Roche Molecular Diagnostics, Pleasanton, CA, USA), Abbott RealTime High Risk HPV (Abott, Wiesbaden, Germany), and Allplex Respiratory Panel (Seegene, Seoul, Korea).

Abbreviations: CMV, cytomegalovirus; PCR, polymerase chain reaction; EBV, Epstein-Barr virus; HIV-1, human immunodeficiency virus type 1; RT-PCR, reverse transcription-polymerase chain reaction; HPV, human papillomavirus; PIV, parainfluenza virus; RSV, respiratory syncytial virus. 
Table 2. List of manufacturers and kits used by participating institutions in 2020 for qualitative testing of molecular virology

\begin{tabular}{|c|c|c|c|}
\hline Target virus & Manufacturer & Kits & $\begin{array}{c}\text { No. of } \\
\text { institutions }\end{array}$ \\
\hline \multirow[t]{9}{*}{ CMV } & Abbott & Abbott & 1 \\
\hline & BioCore & BioCore CMV PCR Kit & 5 \\
\hline & Biosewoom & Real-Q CMV Kit & 5 \\
\hline & ELITech & ELITech & 1 \\
\hline & Roche & Roche & 1 \\
\hline & Seegene & Seeplex Meningitis-V1 ACE Detection & 3 \\
\hline & LDT & Others & 1 \\
\hline & Others & Others & 3 \\
\hline & & Total & 20 \\
\hline \multirow[t]{8}{*}{ EBV } & Artus (Qiagen) & Qiagen & 1 \\
\hline & BioCore & BioCore EBV PCR Kit & 6 \\
\hline & Biosewoom & Real-Q EBV Kit & 1 \\
\hline & ELITech & EBV ELITe MGB Kit & 1 \\
\hline & Seegene & Seeplex Meningitis-V1 ACE Detection & 3 \\
\hline & LDT & Others & 2 \\
\hline & Others & Others & 2 \\
\hline & & Total & 16 \\
\hline \multirow[t]{3}{*}{ HIV } & Abbott & Not specified & 1 \\
\hline & Roche & Not specified & 2 \\
\hline & & Total & 3 \\
\hline \multirow[t]{9}{*}{ HPV } & Abbott & RealTime High Risk HPV & 3 \\
\hline & Genomica & HPV & 1 \\
\hline & Roche & Cobas 4800 HPV Realtime PCR kit & 14 \\
\hline & & Cobas 4800 HPV Test & 1 \\
\hline & Seegene & Anyplex II HPV 28 Detection Kit & 14 \\
\hline & & Anyplex II HPV HR Detection & 1 \\
\hline & LDT & Others & 2 \\
\hline & Others & Others & 10 \\
\hline & & Total & 46 \\
\hline \multirow[t]{10}{*}{ Adenovirus } & Biomerieux & BioFire (bioMerieux) & 4 \\
\hline & Biosewoom & Real-Q RV Detection kit & 7 \\
\hline & LG Chem & Advansure RV Real-time RT-PCR & 24 \\
\hline & & Advansure RV-Plus Real-time RT-PCR & 16 \\
\hline & Luminex & Luminex & 2 \\
\hline & Seegene & Allplex Respiratory Panel 1, 2, 3 & 37 \\
\hline & & Anyplex II RV16 & 4 \\
\hline & LDT & Others & 1 \\
\hline & Others & Others & 2 \\
\hline & & Total & 97 \\
\hline
\end{tabular}


Table 2. Continued

\begin{tabular}{|c|c|c|c|}
\hline Target virus & Manufacturer & Kits & $\begin{array}{c}\text { No. of } \\
\text { institutions }\end{array}$ \\
\hline \multirow[t]{11}{*}{ Influenza virus A, B } & Becton dickinson \& Company & BD VeritorTM System for Rapid Detection of Flu $A+B$ & $1^{*}$ \\
\hline & BioMerieux & BioFire (bioMerieux) & 4 \\
\hline & Biosewoom & Real-Q RV Detection kit & 7 \\
\hline & LG Chem & Advansure RV Real-time RT-PCR & 24 \\
\hline & & Advansure RV-Plus Real-time RT-PCR & 16 \\
\hline & Luminex & Luminex & 2 \\
\hline & Seegene & Allplex Respiratory Panel 1, 2, 3 & 37 \\
\hline & & Anyplex II RV16 & 4 \\
\hline & LDT & LDT & 1 \\
\hline & Others & Others & 6 \\
\hline & & Total & 102 \\
\hline \multirow[t]{10}{*}{ PIV 1-3 } & Biomerieux & BioFire (bioMerieux) & 4 \\
\hline & Biosewoom & Real-Q RV Detection kit & 7 \\
\hline & LG Chem & Advansure RV Real-time RT-PCR & 24 \\
\hline & & Advansure RV-Plus Real-time RT-PCR & 16 \\
\hline & Luminex & Luminex & 2 \\
\hline & Seegene & Allplex Respiratory Panel 1, 2, 3 & 37 \\
\hline & & Anyplex II RV16 & 4 \\
\hline & LDT & LDT & 1 \\
\hline & Others & Others & 2 \\
\hline & & Total & 97 \\
\hline \multirow[t]{10}{*}{ RSV } & Biomerieux & BioFire (bioMerieux) & 4 \\
\hline & Biosewoom & Real-Q RV Detection kit & 7 \\
\hline & LG Chem & Advansure RV Real-time RT-PCR & 24 \\
\hline & & Advansure RV-Plus Real-time RT-PCR & 16 \\
\hline & Luminex & Luminex & 2 \\
\hline & Seegene & Allplex Respiratory Panel 1, 2, 3 & 37 \\
\hline & & Anyplex II RV16 & 4 \\
\hline & LDT & LDT & 1 \\
\hline & Others & Others & 2 \\
\hline & & Total & 97 \\
\hline
\end{tabular}

The kits were purchased from the following companies: Abbott (Abbott, Des Plaines, IL, USA), BioCore (BioCore, Seoul, Korea), BioMerieux (BioMerieux, Marcy l'Etoile, France), Biosewoom (Biosewoom, Seoul, Korea), ELITech (ELITech, Puteaux, France), Genomica (Genomica, Madrid, Spain), LG Chem (LG Chem, Seoul, Korea), Luminex (Luminex, Austin, TX, USA), QIAGEN (QIAGEN, Hilden, Germany), Roche (Roche Molecular Diagnostics, Pleasanton, CA), and Seegene (Seegene, Seoul, Korea).

Abbreviations: CMV, cytomegalovirus; PCR, polymerase chain reaction; LDT, laboratory developed test; EBV, Epstein-Barr virus; HIV, human immunodeficiency virus; HPV, human papillomavirus; RT-PCR, reverse transcription-polymerase chain reaction; PIV, parainfluenza virus; RSV, respiratory syncytial virus.

${ }^{*}$ The BD Veritor System for Rapid Detection of Flu A+B was not a molecular detection method but a rapid antigen test. Therefore, this institution did not meet standards for molecular proficiency testing of influenza. 
Table 3. Proficiency testing results for qualitative testing of CMV, EBV, HPV, and HIV from 2016 to 2020

\begin{tabular}{|c|c|c|c|c|c|c|c|c|c|c|c|c|c|c|c|c|c|}
\hline \multirow{2}{*}{ Trial } & \multirow{2}{*}{$\begin{array}{c}\text { Sample } \\
\text { no. }\end{array}$} & \multicolumn{4}{|c|}{ CMV } & \multicolumn{4}{|c|}{ EBV } & \multicolumn{4}{|c|}{ HPV } & \multicolumn{4}{|c|}{ HIV } \\
\hline & & 1 & $P$ & $C$ & $\%$ & 1 & $P$ & $C$ & $\%$ & 1 & $P$ & $\mathrm{C}$ & $\%$ & I & $P$ & C & $\%$ \\
\hline \multirow[t]{3}{*}{2016 1st } & 1 & $p$ & 25 & 25 & 100 & $p$ & 15 & 15 & 100 & $\mathrm{p}$ & 43 & 42 & 98 & $\mathrm{n}$ & 3 & 3 & 100 \\
\hline & 2 & $\mathrm{n}$ & 25 & 24 & 96 & $\mathrm{p}$ & 15 & 15 & 100 & $\mathrm{n}$ & 43 & 43 & 100 & $p$ & 3 & 2 & 67 \\
\hline & 3 & $p$ & 25 & 25 & 100 & $\mathrm{n}$ & 15 & 15 & 100 & & & & & $\mathrm{p}$ & 3 & 2 & 67 \\
\hline \multirow[t]{3}{*}{2016 2nd } & 1 & $p$ & 24 & 24 & 100 & $p$ & 15 & 15 & 100 & $\mathrm{n}$ & 43 & 43 & 100 & $\mathrm{p}$ & 3 & 3 & 100 \\
\hline & 2 & $p$ & 24 & 23 & 96 & $p$ & 15 & 15 & 100 & $\mathrm{p}$ & 43 & 43 & 100 & $\mathrm{p}$ & 3 & 3 & 100 \\
\hline & 3 & $\mathrm{n}$ & 24 & 24 & 100 & $\mathrm{n}$ & 15 & 15 & 100 & & & & & $\mathrm{n}$ & 3 & 3 & 100 \\
\hline \multirow[t]{3}{*}{2017 1st } & 1 & $\mathrm{n}$ & 23 & 23 & 100 & $\mathrm{n}$ & 16 & 16 & 100 & $\mathrm{n}$ & 45 & 45 & 100 & $\mathrm{n}$ & 5 & 5 & 100 \\
\hline & 2 & $p$ & 23 & 23 & 100 & $\mathrm{p}$ & 16 & 15 & 94 & $\mathrm{p}$ & 45 & 45 & 100 & $\mathrm{p}$ & 5 & 4 & 80 \\
\hline & 3 & $p$ & 23 & 23 & 100 & $p$ & 16 & 16 & 100 & & & & & $\mathrm{p}$ & 5 & 4 & 80 \\
\hline \multirow[t]{3}{*}{2017 2nd } & 1 & $\mathrm{n}$ & 23 & 23 & 100 & $\mathrm{n}$ & 16 & 16 & 100 & $\mathrm{n}$ & 45 & 45 & 100 & $\mathrm{n}$ & 4 & 4 & 100 \\
\hline & 2 & $p$ & 23 & 23 & 100 & $p$ & 16 & 16 & 100 & $\mathrm{p}$ & 45 & 45 & 100 & $\mathrm{p}$ & 4 & 4 & 100 \\
\hline & 3 & $p$ & 20 & 20 & 100 & $p$ & 16 & 14 & 88 & & & & & $p$ & 4 & 4 & 100 \\
\hline \multirow[t]{3}{*}{2018 1st } & 1 & $\mathrm{n}$ & 20 & 20 & 100 & $\mathrm{n}$ & 13 & 13 & 100 & $\mathrm{n}$ & 44 & 44 & 100 & $\mathrm{n}$ & 5 & 5 & 100 \\
\hline & 2 & $\mathrm{p}$ & 20 & 20 & 100 & $\mathrm{p}$ & 13 & 13 & 100 & $\mathrm{p}$ & 44 & 44 & 100 & $\mathrm{p}$ & 5 & 3 & 60 \\
\hline & 3 & $p$ & 21 & 21 & 100 & $p$ & 13 & 13 & 100 & & & & & $p$ & 5 & 3 & 60 \\
\hline \multirow[t]{3}{*}{2018 2nd } & 1 & $p$ & 21 & 20 & 95 & $\mathrm{p}$ & 14 & 14 & 100 & $\mathrm{n}$ & 44 & 44 & 100 & $n$ & 5 & 4 & 80 \\
\hline & 2 & $\mathrm{p}$ & 21 & 21 & 100 & $p$ & 14 & 14 & 100 & $\mathrm{p}$ & 44 & 44 & 100 & $\mathrm{p}$ & 5 & 4 & 80 \\
\hline & 3 & $\mathrm{n}$ & 21 & 20 & 95 & $\mathrm{n}$ & 14 & 14 & 100 & & & & & $\mathrm{p}$ & 5 & 5 & 100 \\
\hline \multirow[t]{3}{*}{2019 1st } & 1 & $\mathrm{n}$ & 21 & 21 & 100 & $\mathrm{n}$ & 15 & 15 & 100 & $\mathrm{n}$ & 43 & 43 & 100 & $\mathrm{n}$ & 5 & 5 & 100 \\
\hline & 2 & $p$ & 21 & 21 & 100 & $p$ & 15 & 15 & 100 & $\mathrm{p}$ & 43 & 43 & 100 & $\mathrm{p}$ & 5 & 5 & 100 \\
\hline & 3 & $\mathrm{p}$ & 21 & 18 & 86 & $\mathrm{p}$ & 15 & 15 & 100 & & & & & $\mathrm{p}$ & 5 & 5 & 100 \\
\hline \multirow[t]{3}{*}{2019 2nd } & 1 & $\mathrm{n}$ & 21 & 21 & 100 & $\mathrm{n}$ & 15 & 15 & 100 & $\mathrm{n}$ & 43 & 43 & 100 & $\mathrm{n}$ & 4 & 4 & 100 \\
\hline & 2 & $\mathrm{p}$ & 21 & 20 & 95 & $\mathrm{p}$ & 15 & 15 & 100 & $\mathrm{p}$ & 43 & 43 & 100 & $\mathrm{p}$ & 4 & 4 & 100 \\
\hline & 3 & $p$ & 21 & 17 & 81 & $p$ & 15 & 15 & 100 & & & & & $\mathrm{p}$ & 4 & 4 & 100 \\
\hline \multirow[t]{3}{*}{2020 1st } & 1 & $\mathrm{p}$ & 20 & 20 & 100 & $\mathrm{n}$ & 16 & 16 & 100 & $\mathrm{p}$ & 46 & 46 & 100 & $\mathrm{p}$ & 3 & 3 & 100 \\
\hline & 2 & $n$ & 20 & 20 & 100 & $\mathrm{p}$ & 16 & 16 & 100 & $n$ & 46 & 46 & 100 & $\mathrm{p}$ & 3 & 3 & 100 \\
\hline & 3 & $\mathrm{p}$ & 20 & 20 & 100 & $p$ & 16 & 16 & 100 & & & & & $\mathrm{n}$ & 3 & 3 & 100 \\
\hline \multirow[t]{3}{*}{2020 2nd } & 1 & $\mathrm{p}$ & 21 & 21 & 100 & $n$ & 16 & 15 & 94 & $\mathrm{n}$ & 47 & 47 & 100 & $\mathrm{p}$ & 3 & 3 & 100 \\
\hline & 2 & $\mathrm{n}$ & 21 & 21 & 100 & $\mathrm{p}$ & 16 & 15 & 94 & $\mathrm{p}$ & 47 & 47 & 100 & $\mathrm{p}$ & 3 & 3 & 100 \\
\hline & 3 & $\mathrm{p}$ & 21 & 21 & 100 & $\mathrm{p}$ & 16 & 15 & 94 & & & & & $\mathrm{n}$ & 3 & 3 & 100 \\
\hline
\end{tabular}

Abbreviations: CMV, cytomegalovirus; EBV, Epstein-Barr virus; HPV, human papillomavirus; HIV, human immunodeficiency virus; I, intended response; $P$, number of participating institutions; $C$, correct response; $p$, positive; $n$, negative.

음성으로 보고하였고, 1 기관이 음성 검체를 위양성으로 보고하였 다. 2017년 1차에는 adenovirus에 대해 참가한 90개 기관 중에 LG Chem사, 검사실 자체개발검사, Luminex와 기타 검사를 이 용하는 22기관(24.4\%)이 위음성 보고를 하였다. 2017년 2차에 는 adenovirus 음성 검체를 30기관이 양성 보고하였는데, 이는 정도관리물질 배양 시 낮은 농도의 adenovirus 오염에 의한 것으
로 보인다. Influenza virus 양성 검체에 대해서 3 개 기관이 위음 성 보고를 하였고, PIV 양성 검체에 대해서 3기관이 위음성 보고를 하였다. 2018년 1차에는 influenza virus A 양성 검체에 대해서 위양성 1 건이 있었으며 검사실 자체개발검사로 보고한 결과였다. influenza virus 음성 검체에 대해 1 기관이 위양성으로 보고하였 다. 2018년 2차에서는 influenza virus A에 대해 1 기관이 위양성 
Table 4. Proficiency testing results for qualitative testing of respiratory viruses from 2016 to 2020

\begin{tabular}{|c|c|c|c|c|c|c|c|c|c|c|c|c|c|c|c|c|c|}
\hline \multirow{2}{*}{ Trial } & \multirow{2}{*}{$\begin{array}{c}\text { Sample } \\
\text { no. }\end{array}$} & \multicolumn{4}{|c|}{ Influenza virus A, B } & \multicolumn{4}{|c|}{ Adenovirus } & \multicolumn{4}{|c|}{$\begin{array}{c}\text { Parainfluenza } 1,2,3 \\
\text { virus }\end{array}$} & \multicolumn{4}{|c|}{$\begin{array}{c}\text { Respiratory syncytial } \\
\text { virus }\end{array}$} \\
\hline & & I & $P$ & C & $\%$ & I & $P$ & $\mathrm{C}$ & $\%$ & I & $P$ & C & $\%$ & I & $\mathrm{P}$ & $\mathrm{C}$ & $\%$ \\
\hline \multirow[t]{2}{*}{2016 1st } & 1 & $\mathrm{p}$ & 73 & 63 & 86 & $\mathrm{n}$ & 70 & 70 & 100 & $\mathrm{n}$ & 70 & 70 & 100 & $\mathrm{n}$ & 71 & 71 & 100 \\
\hline & 2 & $\mathrm{n}$ & 72 & 72 & 100 & $\mathrm{n}$ & 70 & 70 & 100 & $\mathrm{n}$ & 70 & 70 & 100 & $\mathrm{p}$ & 72 & 71 & 99 \\
\hline \multirow[t]{2}{*}{2016 2nd } & 1 & $\mathrm{n}$ & 71 & 71 & 100 & $\mathrm{n}$ & 73 & 73 & 100 & $\mathrm{n}$ & 71 & 71 & 100 & $\mathrm{p}$ & 73 & 43 & 59 \\
\hline & 2 & $\mathrm{n}$ & 71 & 71 & 100 & $\mathrm{p}$ & 73 & 72 & 99 & $\mathrm{n}$ & 71 & 71 & 100 & $\mathrm{n}$ & 73 & 72 & 99 \\
\hline \multirow[t]{2}{*}{2017 1st } & 1 & $\mathrm{n}$ & 88 & 88 & 100 & $\mathrm{n}$ & 90 & 90 & 100 & $\mathrm{n}$ & 88 & 88 & 100 & $\mathrm{n}$ & 90 & 90 & 100 \\
\hline & 2 & $\mathrm{n}$ & 88 & 88 & 100 & $\mathrm{p}$ & 90 & 68 & 76 & $\mathrm{n}$ & 88 & 88 & 100 & $\mathrm{n}$ & 90 & 90 & 100 \\
\hline \multirow[t]{2}{*}{2017 2nd } & 1 & $\mathrm{p}$ & 92 & 89 & 97 & $\mathrm{n}$ & 90 & 90 & 100 & $\mathrm{n}$ & 91 & 91 & 100 & $\mathrm{n}$ & 90 & 90 & 100 \\
\hline & 2 & $\mathrm{n}$ & 92 & 92 & 100 & $\mathrm{p}$ & 90 & 30 & 33 & $\mathrm{p}$ & 91 & 88 & 97 & $n$ & 90 & 90 & 100 \\
\hline \multirow[t]{3}{*}{20181 st } & 1 & $p$ & 96 & 95 & 99 & $\mathrm{n}$ & 92 & 92 & 100 & $\mathrm{n}$ & 93 & 93 & 100 & $\mathrm{n}$ & 93 & 93 & 100 \\
\hline & 2 & $p$ & 96 & 96 & 100 & $n$ & 92 & 92 & 100 & $n$ & 93 & 93 & 100 & $n$ & 93 & 93 & 100 \\
\hline & 3 & $\mathrm{n}$ & 96 & 95 & 99 & $\mathrm{n}$ & 92 & 92 & 100 & $\mathrm{n}$ & 93 & 93 & 100 & $\mathrm{n}$ & 93 & 93 & 100 \\
\hline \multirow[t]{3}{*}{2018 2nd } & 1 & $\mathrm{n}$ & 97 & 96 & 99 & $\mathrm{p}$ & 92 & 92 & 100 & $\mathrm{p}$ & 93 & 85 & 91 & $n$ & 93 & 93 & 100 \\
\hline & 2 & $\mathrm{n}$ & 97 & 97 & 100 & $n$ & 92 & 92 & 100 & $\mathrm{p}$ & 93 & 83 & 89 & $\mathrm{n}$ & 93 & 93 & 100 \\
\hline & 3 & $\mathrm{n}$ & 97 & 97 & 100 & $\mathrm{n}$ & 92 & 92 & 100 & $\mathrm{n}$ & 93 & 93 & 100 & $\mathrm{n}$ & 93 & 93 & 100 \\
\hline \multirow[t]{2}{*}{2019 1st } & 1 & $\mathrm{p}$ & 104 & 103 & 99 & $n$ & 95 & 95 & 100 & $n$ & 95 & 88 & 93 & $\mathrm{n}$ & 96 & 96 & 100 \\
\hline & 2 & $p$ & 104 & 102 & 98 & $n$ & 95 & 95 & 100 & $p$ & 95 & 89 & 94 & $n$ & 96 & 96 & 100 \\
\hline \multirow[t]{3}{*}{2019 2nd } & 1 & $p$ & 104 & 104 & 100 & $n$ & 97 & 97 & 100 & $n$ & 97 & 97 & 100 & $\mathrm{n}$ & 97 & 97 & 100 \\
\hline & 2 & $\mathrm{n}$ & 104 & 103 & 99 & $\mathrm{p}$ & 97 & 97 & 100 & $\mathrm{n}$ & 97 & 97 & 100 & $\mathrm{n}$ & 97 & 97 & 100 \\
\hline & 3 & $\mathrm{n}$ & 104 & 103 & 99 & $\mathrm{n}$ & 97 & 97 & 100 & $\mathrm{n}$ & 97 & 97 & 100 & $\mathrm{n}$ & 97 & 97 & 100 \\
\hline \multirow[t]{3}{*}{2020 1st } & 1 & $\mathrm{n}$ & 102 & 102 & 100 & $\mathrm{n}$ & 97 & 97 & 100 & $\mathrm{n}$ & 97 & 97 & 100 & $\mathrm{n}$ & 97 & 97 & 100 \\
\hline & 2 & $\mathrm{p}$ & 102 & 102 & 100 & $n$ & 97 & 97 & 100 & $n$ & 97 & 97 & 100 & $n$ & 97 & 97 & 100 \\
\hline & 3 & $\mathrm{n}$ & 102 & 102 & 100 & $p$ & 97 & 97 & 100 & $\mathrm{n}$ & 97 & 97 & 100 & $\mathrm{n}$ & 97 & 97 & 100 \\
\hline \multirow[t]{3}{*}{2020 2nd } & 1 & $n$ & 102 & 102 & 100 & $\mathrm{n}$ & 97 & 97 & 100 & $n$ & 97 & 97 & 100 & $n$ & 97 & 97 & 100 \\
\hline & 2 & $\mathrm{p}$ & 102 & 102 & 100 & $\mathrm{n}$ & 97 & 97 & 100 & $\mathrm{n}$ & 97 & 97 & 100 & $\mathrm{n}$ & 97 & 97 & 100 \\
\hline & 3 & $\mathrm{n}$ & 102 & 102 & 100 & $\mathrm{n}$ & 97 & 97 & 100 & $\mathrm{p}$ & 97 & 96 & 99 & $\mathrm{n}$ & 97 & 97 & 100 \\
\hline
\end{tabular}

Abbreviations: I, intended response; $\mathrm{P}$, number of participating institutions; $\mathrm{C}$, correct response; $\mathrm{p}$, positive; $\mathrm{n}$, negative.

보고하였고, PIV 2개 양성 검체에 대해 각각 8 기관과 10 기관이 위 음성으로 보고하였으며, 이 중 첫번째 8기관은 모두 Seegene사 의 Anyplex II RV16를 사용하는 기관이었고, 두번째 10 기관 중 8 기관도 Seegene사의 제품을 사용하여 결과를 보고한 기관이었 다. 2019년 1차에서는 influenza virus 양성 검체 2개에 대해서 각각 1 기관과 2 기관이 위음성으로 보고하였고, PIV 양성 검체에 대해 7 기관이 위양성으로, 음성 검체에 대해 6 기관이 위음성으로 보고하였다. 2019년 2차에는 influenza virus에 대해서 1기관이 2 개 음성 검체를 위양성으로 보고하였으며, RSV에 대해 1 기관이 음성 검체를 위양성으로 보고하였다. 2020년 1차에는 모든 기관 이 정답률 $100 \%$ 를 보였으며, 2차에서는 PIV 양성 검체에 대해 1
기관이 위음성으로 보고하였다.

\section{고찰}

2016년에서 2020년 기간에 정성 바이러스 분자검사의 신빙도 조사사업 결과 대부분의 검체에서 consensus를 보이는 결과를 보여 만족스러운 수준의 신빙도조사가 이루어졌다. 다만, 호흡기 바이러스는 정도관리물질 제조 시 낮은 농도의 adenovirus 오염 이 있었다. 이러한 정도관리물질 제조에 있어 오염 방지를 위한 노 력과 제조 후 검증의 필요성을 시사한다.

다중 PCR을 이용하여 정성검사를 시행하는 호흡기바이러스 이 
외에는 CMV, HIV-1, EBV, HPV는 검사기관의 차이가 거의 없거나 소폭 감소하고 있었다. $\mathrm{EBV}$ 의 경우에는 정성검사의 임상적 중요 성이 떨어져, 향후 신빙도조사사업 중단을 고려할 만하다. 다른 정 성검사 항목에 대해서도 향후 검사실 환경의 변화와 연구결과들을 검토하여 정량검사를 시행하도록 유도하는 것이 필요할 수 있겠 다.

Unacceptable한 응답을 보인 경우에 대해서 고찰해보면, influenza virus 검사실 자체개발검사를 시행한 1 개 기관만이 위 음성을 보인 경우가 있었다. 이러한 경우 표적 유전자 검출을 위해 고안한 시발체(primer) 또는 소식자(probe) 부위의 불일치로 인 해 위음성 결과를 보였을 가능성이 있다. 동일한 기관의 같은 회 차에서 양성과 음성을 바꾸어서 보고한 경우가 있어서 사무상 착 오(clerical error)에 의한 가능성을 생각할 수 있었다. 뿐만 아니 라 검사항목의 착오도 관찰할 수 있었는데, HIV-1 신속항체검사를 시행한 후 HIV-1 분자검사 결과로 입력한 경우나 influenza virus 신속항원검사(예, BD Veritor)를 실시한 후 influenza virus 분자
검사에 결과를 보고한 경우도 있었다. 이러한 사무상 착오로 인한 문제 발생 가능성에 대해서는 안내서와 교육을 통해 교정이 필요 하다.

2016년부터 2020년까지 대한임상검사정도관리협회에 의해 이 뤄진 신빙도조사사업에서 바이러스 분자검사 항목 중 정성 바이러 스 분자검사에 대한 응답은 전반적으로 우수하였다. 지난 5년간의 신빙도조사사업을 분석함으로써 신빙도조사가 검사실의 정성 분 자 바이러스 검사의 보고를 개선할 수 있는 점과 정도관리물질의 적절한 제조의 중요성을 확인할 수 있었다.

\section{ORCID}

Kuenyoul Park https://orcid.org/0000-0003-3950-4946

Mi-Na Kim https://orcid.org/0000-0002-4624-6925

Heungsup Sung https://orcid.org/0000-0002-6062-4451

\section{REFERENCES}

1. Hodinka RL. Human cytomegalovirus. In: Carroll KC, Pfaller MA, Landry ML, McAdam AJ, Patel R, Richter SS, et al. Manual of clinical microbiology. 12th ed. Washington (DC): ASM Press, 2019:1779.

2. Gartner BC, Baldanti F. Epstein-Barr virus. In: Carroll KC, Pfaller MA, Landry ML, McAdam AJ, Patel R, Richter SS, et al. Manual of clinical microbiology. 12th ed. Washington (DC): ASM Press, 2019:1802.

3. Cuschieri K, Unger ER. Human papillomaviruses. In: Carroll KC, Pfaller MA, Landry ML, McAdam AJ, Patel R, Richter SS, et al. Manual of clinical microbiology. 12th ed. Washington (DC): ASM Press, 2019:1854-5.

4. Centers for Disease Control (CDC). Interpretation and use of the western blot assay for serodiagnosis of human immunodeficiency virus type 1 infections. MMWR Suppl 1989;38:1-7.

5. Ethridge SF, Hart C, Hanson DL, Parker MM, Sullivan TJ, Bennett B, et al. Performance of the Aptima HIV-1 RNA qualitative assay with 16- and 32-member specimen pools. J Clin Microbiol 2010;48:3343-5.

6. Fiebig EW, Wright DJ, Rawal BD, Garrett PE, Schumacher RT, Peddada L, et al. Dynamics of HIV viremia and antibody seroconversion in plasma donors: implications for diagnosis and staging of primary HIV infection. AIDS 2003;17:18719.

7. Owen SM. Human immunodeficiency virus. In: Carroll KC, Pfaller MA, Landry ML, McAdam AJ, Patel R, Richter SS, et al. Manual of clinical microbiology. 12th ed. Washington (DC): ASM Press, 2019:1482.

8. Hanson KE, Azar MM, Banerjee R, Chou A, Colgrove RC, Ginocchio CC, et al. Molecular testing for acute respiratory tract infections: clinical and diagnostic recommendations from the IDSA's Diagnostics Committee. Clin Infect Dis 2020;71:2744-51. 